\title{
Minimum 2-Year Experience with Magnetically Controlled Growing Rods for the Treatment of Early-Onset Scoliosis: A Systematic Review
}

\author{
Ai-Min Wu ${ }^{1,2,3}$, Jason Pui Yin Cheung ${ }^{2}$, Kenneth Man Chee Cheung ${ }^{2}$, Jia-Liang Lin ${ }^{1}$, \\ Hai-Ming Jin ${ }^{1}$, Dong Chen ${ }^{1}$, Xiang-Yang Wang ${ }^{1}$, Jie Zhao ${ }^{3}$, Kenny Yat Hong Kwan ${ }^{2}$ \\ ${ }^{1}$ Department of Spine Surgery, Zhejiang Spine Surgery Centre, Orthopaedic Hospital, The Second Affiliated Hospital and Yuying Children's Hospital of \\ Wenzhou Medical University, Zhejiang Provincial Key Laboratory of Orthopaedics, Wenzhou, China \\ ${ }^{2}$ Department of Orthopaedics and Traumatology, Li Ka Shing Faculty of Medicine, The University of Hong Kong, Hong Kong, SAR \\ ${ }^{3}$ Department of Orthopaedics, Ninth People's Hospital, Shanghai Jiaotong University School of Medicine, Shanghai Key Laboratory of Orthopaedic \\ Implants, Shanghai, China
}

Magnetically controlled growing rods have been used to treat early-onset scoliosis for the last 9 years; however, few studies have been published, with only short-term follow-up. The aim of the present study is to systematically review the outcomes of magnetically controlled growing rods in the treatment of early-onset scoliosis with a minimum of 2-year follow-up. Studies were included if patients with early-onset scoliosis (scoliosis diagnosed before 10 years of age) underwent implantation of magnetically controlled growing rods with a minimum of 2-year follow-up. The literature review and data extraction followed the established preferred reporting items for systematic review and meta-analysis guidelines. Data of distraction frequency, number of distractions, distracted length, Cobb angle, kyphosis, T1-T12 length, and T1-S1 length preoperatively, postoperatively, and at final follow-up were collected. Data regarding complications and unplanned reoperations were also extracted. The mean values of these parameters were calculated, or pooled meta-analysis was performed if available. Ten articles were included in this systematic review, with a total of 116 patients and a follow-up period between 23 and 61 months. The mean preoperative Cobb angle and kyphosis angle were $60.1^{\circ}$ and $38.0^{\circ}$, respectively, and improved to $35.4^{\circ}$ and $26.1^{\circ}$ postoperatively. At final follow-up, the Cobb and kyphosis angles were maintained at $36.9^{\circ}$ and $36.0^{\circ}$, respectively. The average preoperative T1-T12 and T1-S1 lengths were $180.6 \mathrm{~mm}$ and $293.6 \mathrm{~mm}$, respectively, and increased to $198.3 \mathrm{~mm}$ and $320.3 \mathrm{~mm}$ postoperatively. T1-T12 and T1-S1 lengths were $212.3 \mathrm{~mm}$ and $339.3 \mathrm{~mm}$ at final follow-up, respectively. The overall rate of patients with complications was $48 \%$ (95\% confidence interval [CI], 0.38-0.58) and unplanned reoperation $44 \%(95 \% \mathrm{Cl}, 0.33-0.55)$ after sensitivity analysis. The current evidence from different countries with a minimum of a 2-year follow-up suggests that magnetically controlled growing rods are an effective technique to treat pediatric scoliosis and promote spine growth. However, nearly half of patients still developed complications or required unplanned reoperations.

Keywords: Early-onset scoliosis; Pediatric scoliosis; Magnetically controlled growing rods; Systematic review

Received Oct 20, 2018; Accepted Dec 13, 2018

Correspondence author: Kenny Yat Hong Kwan

Department of Orthopaedics and Traumatology, Li Ka Shing Faculty of Medicine, The University of Hong Kong, Hong Kong, SAR

Tel: +852-2255-4654, Fax: +852-2817-4392, E-mail: kyhkwan@hku.hk

*This work was acquired the excellent oral presentation award of the 11th Congress of Chinese Association of Orthopaedic Surgeons (2018, China, Hangzhou). 


\section{Introduction}

Early-onset scoliosis is defined as scoliosis diagnosed before 10 years of age $[1,2]$ and has multiple etiologies, including neuromuscular, congenital, syndromic, and idiopathic. The progression of early-onset scoliosis results in cosmetic disfigurement, cardiopulmonary disorders, and early mortality [3]. Surgical treatment is indicated for children with progressive curves of $>45^{\circ}[4,5]$. The aim of the surgical treatment is to stop the progression of the curve and allow for growth of the spine, lungs, and thoracic cage. Therefore, the spinal fusion technique is not recommended for patients with early-onset scoliosis (scoliosis diagnosed before 10 years of age) who still have growth potential.

The consensus standard technique is a growth-sparing technique using traditional growing rods to treat earlyonset scoliosis in patients with remaining growth potential $[4,6]$. However, the major disadvantage of traditional growing rods is their requirement for operative distraction under general anesthesia every 6 months, meaning that the entirety of treatment may require more than 15 operations [1,7], which adds considerable cost and leads to loss of schooling for the children because of the repeated hospital admissions. Also, this technique has a high rate of complications and unplanned reoperations $[2,7,8]$.

A novel device known as magnetically controlled growing rods was developed to treat pediatric scoliosis to avoid regular and repeated operations under general anesthesia $[9,10]$. This method has shown satisfactory preliminary clinical outcomes [11-14], and the use of ultrasound to monitor the distraction avoids radiation exposure $[15,16]$. However, most studies in the literature have minimum follow-up periods of less than 2 years [17-22]. Additionally, the number of cases reported in the most recent literature is less than 30 , with most studies reporting less than 10 cases. Moreover, with the widespread use of magnetically controlled growing rods, the phenomenon of 'the law of diminishing returns,' rod slippage, metallosis, complications, and unplanned reoperations have been reported [23-28]. Therefore, we conducted the present study to systematically review the data on magnetically controlled growing rods for the treatment of early-onset scoliosis with a minimum of 2-year follow-up.

\section{Methods and Materials}

This is a systematic review of previous reports and does not require institutional ethical approval. Our present systematic review was performed in accordance with preferred reporting items for systematic review and metaanalysis (PRISMA) guidelines [29,30] (Supplemental Table 1).

\section{Inclusion and exclusion criteria}

Inclusion criteria were as follows: (1) patients with earlyonset scoliosis diagnosed before 10 years of age, (2) patients who underwent implantation of magnetically controlled growing rods (both primary and conversion cases), and (3) minimum of 2-year follow-up. Exclusion criteria were as follows: (1) studies from the same sites with the same data extracted and (2) review articles.

\section{Search strategy and study selection}

Two authors (A.M.W. and J.L.L.) independently searched the electronic literature database of Medline and Embase for studies relevant to the use of magnetically controlled growing rods in the treatment of early-onset scoliosis from the first report in May 2012 to January 2018. The following keywords were searched: 'magnetically controlled growing rod,' 'magnetic controlled growing rod,' 'magnetic growing rod,' or 'magnetically growing rod.' The 'related articles' function was also used in the search to access additional references. Also, references from previous systematic reviews were manually searched to avoid initially overlooked publications. After the two authors independently assessed the potential eligible studies, any disagreements were discussed and resolved by a third independent author (K.Y.H.K). An updated search was performed on June 21, 2018, to include the most recent studies.

\section{Data collection}

The characteristics and results of the included studies were extracted by two independent reviewers (A.M.W., H.M.J.). The following information was included: author, year of publication, region/country, number of cases, age, sex, study design, follow-up duration, distraction frequency, number of distractions, distracted length, Cobb angle, kyphosis, T1-T12 length, T1-S1 length, number of 
complications, and frequency of unplanned reoperations.

\section{Risk of bias assessment}

The risk of bias of the included studies was assessed by the Joanna Briggs Institute (JBI) critical appraisal checklist for case series [31], which has a total of nine items (Supplemental Table 2). The judgments of reviewers were classified as 'yes,' 'no,' 'unclear,' or 'not available.'

\section{Statistical analysis}

Data regarding Cobb angle, kyphosis angle, T1-T12 length, T1-S1 length at preoperative, postoperative, and final follow-up were extracted from every included study. Data on primary and revision cases were extracted separately if data in the originally included studies were reported separately. The mean values of the above parameters were calculated and presented as a line chart to depict changes at different follow-up time points. The pooled analysis of complications and unplanned reoperations was performed on STATA software ver. 12.0 (Stata Corp., College Station, TX, USA). A fixed-effects model was used to combine the data from individual studies. Heterogeneity was assessed using the $I^{2}$ and $\chi^{2}$. If the $p$-value of $\chi^{2}$ test was $<0.10$ or $I^{2}>50 \%$, a sensitivity analysis was conducted by removing a study and evaluating whether the other results would be markedly affected.

\section{Results}

A total of 128 potential studies were identified through PubMed $(n=66)$, Embase $(n=57)$, and the Cochrane library $(n=5)$. After excluding 41 duplicate articles, the remaining 87 articles were screened by title and abstract, which eliminated 53 unrelated articles or conference abstracts. In total, 34 articles were analyzed for full-text review. The studies of Cheung et al. [15] and Akbarnia et al. [32] were not included in the present systematic review because two other studies from the same sites (but with more cases) were already included in the analysis [25,33]. Eight articles from seven medical sites were included first [13,14,25,33-37]. An updated search yielded two new articles [38,39], and the article from Cheung et al. [13] was replaced by their new updated article [24] which included more cases. Although the cases from Cheung et al. [24] and Kwan et al. [25] were from the same site, only data of
PubMed PRISMA 2009 Flow Diagram

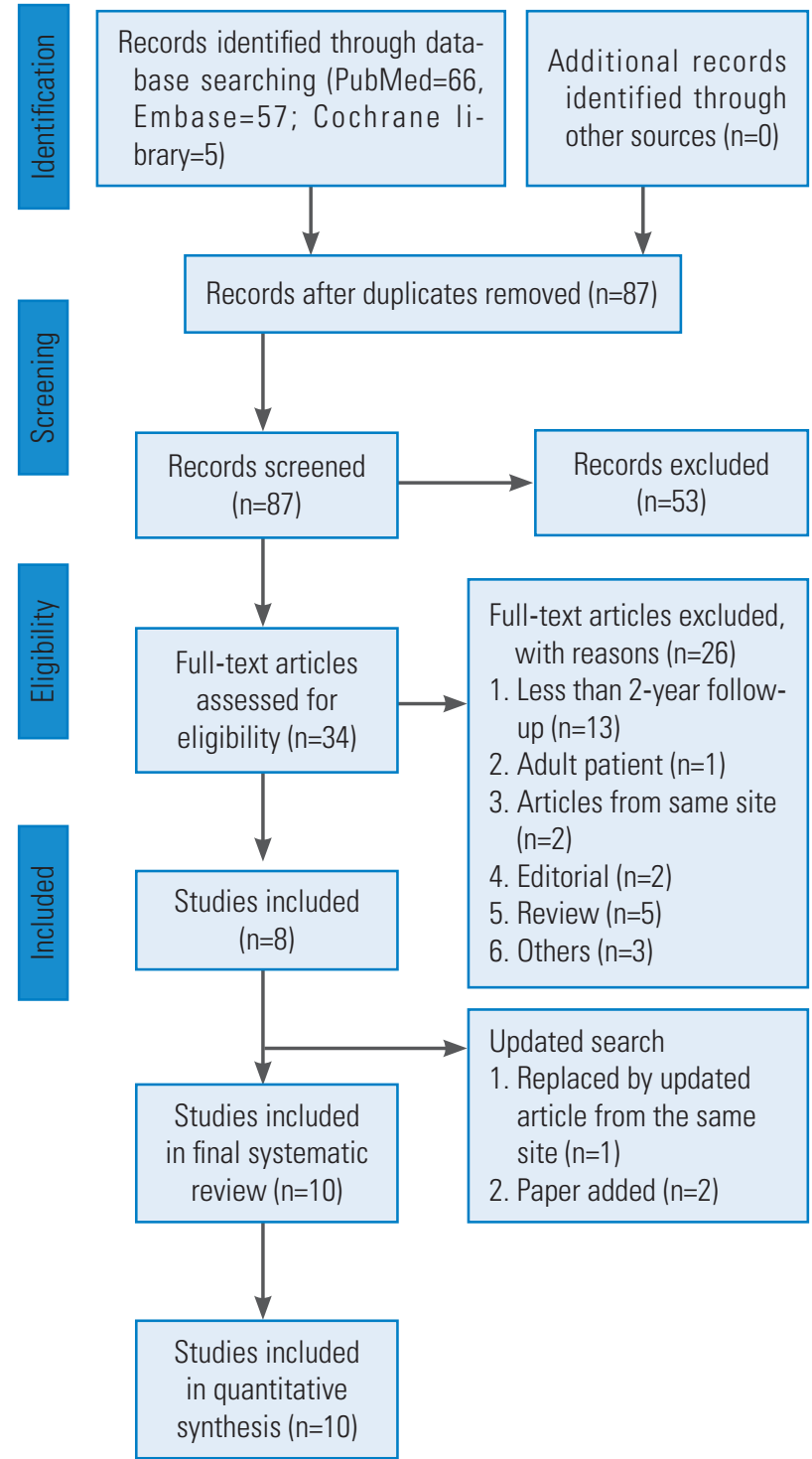

Fig. 1. The PRISMA flow diagram of articles selection. PRISMA, preferred reporting items for systematic review and meta-analysis. From Moher et al. PLoS Med 2009;6:e1000097 [30].

the Cobb angle, complications, and unplanned reoperations were reported in the study by Kwan et al. [25]; therefore, the study by Cheung et al. [24] was also included to analyze kyphosis data, T1-T12 length, and T1-S1 length. Finally, 10 articles were included in the present systemic review and quantitative analysis. The PRISMA flow diagram of article selection is shown in Fig. 1.

\section{Characteristics of included studies}

The first article regarding magnetically controlled growing rods for treatment of early-onset scoliosis was published 


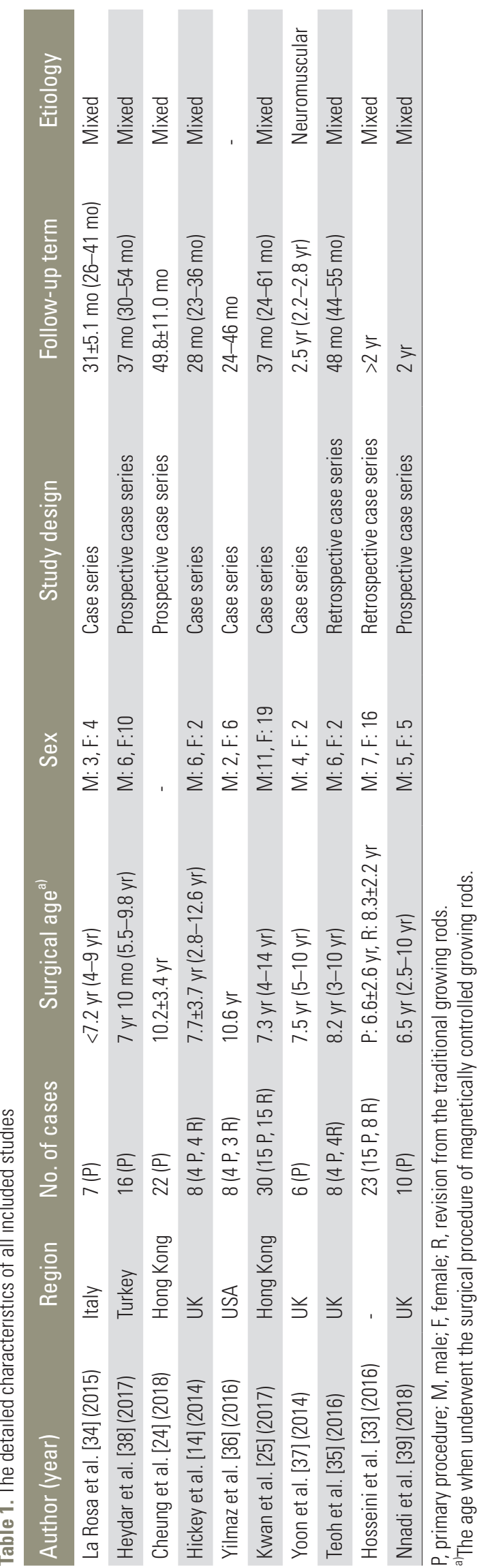

in Lancet in 2012 [13] and contained only two cases with a follow-up duration of 2 years. Ten publications included a total of 116 patients (50 males and 66 females) [14,24,25,33-39]. The cases from articles by Cheung et al. [24] and Kwan et al. [25] were counted only once. All studies had a minimum follow-up period of 2 years (range, 24-61 months), except for one case in Hickey et al. [14] with a 23-month follow-up; this was also included in the present systematic review after discussion among the authors. The detailed characteristics of all included studies are shown in Table 1. The JBI critical appraisal outcomes are summarized in Supplement Table 2 in the supplement.

\section{Cobb angle and kyphosis}

Nine studies reported the Cobb angle preoperatively, postoperatively, and at the final follow-up [14,24,25,3335,37-39]. However, since the articles by Cheung et al. [24] and Kwan et al. [25] were from the same site, we only used the Cobb angle data from Kwan et al. [25] for quantitative synthesis, yielding a total of 108 cases. The average

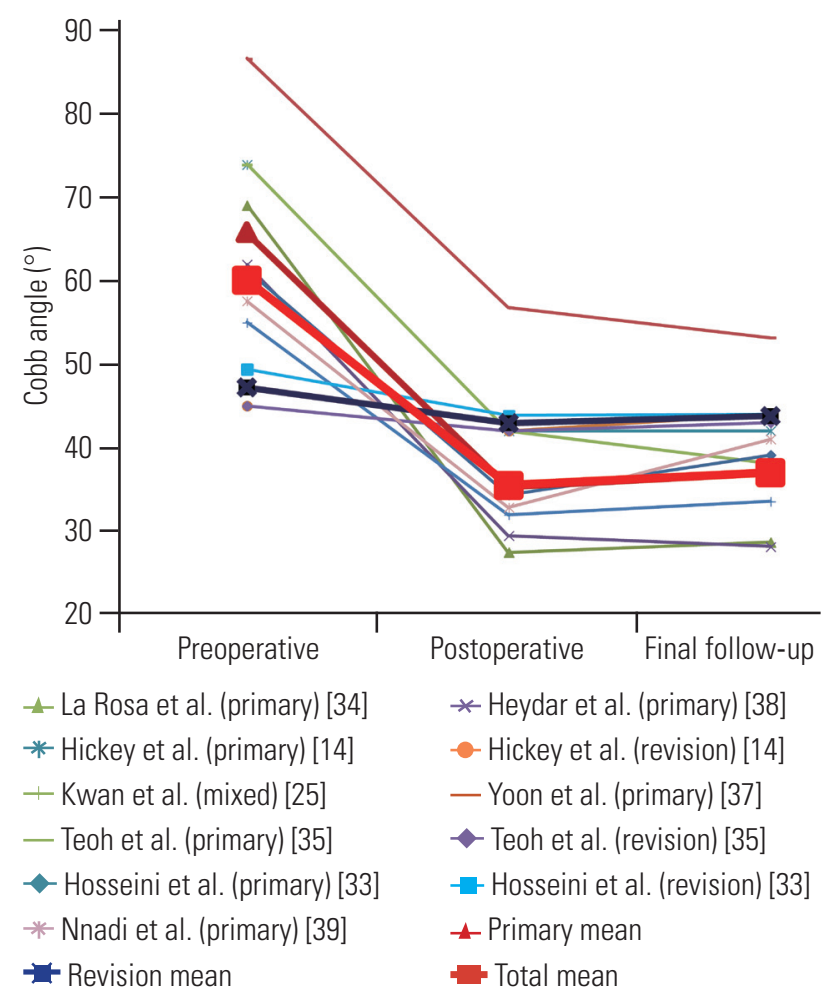

Fig. 2. Average Cobb angle was $60.1^{\circ}$ preoperatively, changed to $35.4^{\circ}$ postoperatively, and was maintained at $36.9^{\circ}$ at final follow-up. The average Cobb angles of primary and revision subgroup were $65.9^{\circ}$ and $47.2^{\circ}$ preoperatively, changed to $35.2^{\circ}$ and $42.9^{\circ}$ postoperatively, and maintained at $36.9^{\circ}$ and $43.8^{\circ}$ at the final follow-up, respectively. 
Cobb angle was $60.1^{\circ}$ preoperatively and improved to $35.4^{\circ}$ postoperatively; the Cobb angle was maintained at $36.9^{\circ}$ at the final follow-up. The average Cobb angles of the primary and revision subgroups were $65.9^{\circ}$ and $47.2^{\circ}$ preoperatively, changed to $35.2^{\circ}$ and $42.9^{\circ}$ postoperatively, and maintained at $36.9^{\circ}$ and $43.8^{\circ}$ at the final follow-up, respectively (Fig. 2).

Four studies reported a kyphotic angle for a total of 68 cases $[24,33,34,38]$. The average kyphotic angle was $38.0^{\circ}$ preoperatively and changed to $26.1^{\circ}$ postoperatively; a kyphotic angle of $36.0^{\circ}$ was observed at the final follow-up. The average kyphotic angle in the primary subgroup was $37.8^{\circ}$ preoperatively, changed to $24.7^{\circ}$ postoperatively, and was $36.3^{\circ}$ at the final follow-up (Fig. 3).

\section{T1-T12 and T1-S1 length}

Five studies reported T1-T12 length data, for a total of 78 cases [24,33,34,38,39]. The average preoperative T1T12 length was $180.6 \mathrm{~mm}$, which increased to $198.3 \mathrm{~mm}$ postoperatively. At the final follow-up, T1-T12 length was $212.3 \mathrm{~mm}$. The primary subgroup data could be combined, yielding mean values of $181.7 \mathrm{~mm}$ preoperatively, which changed to $199.7 \mathrm{~mm}$ postoperatively and was $216.0 \mathrm{~mm}$ at the final follow-up (Fig. 4).

Six studies reported T1-S1 length data, for a total of 86

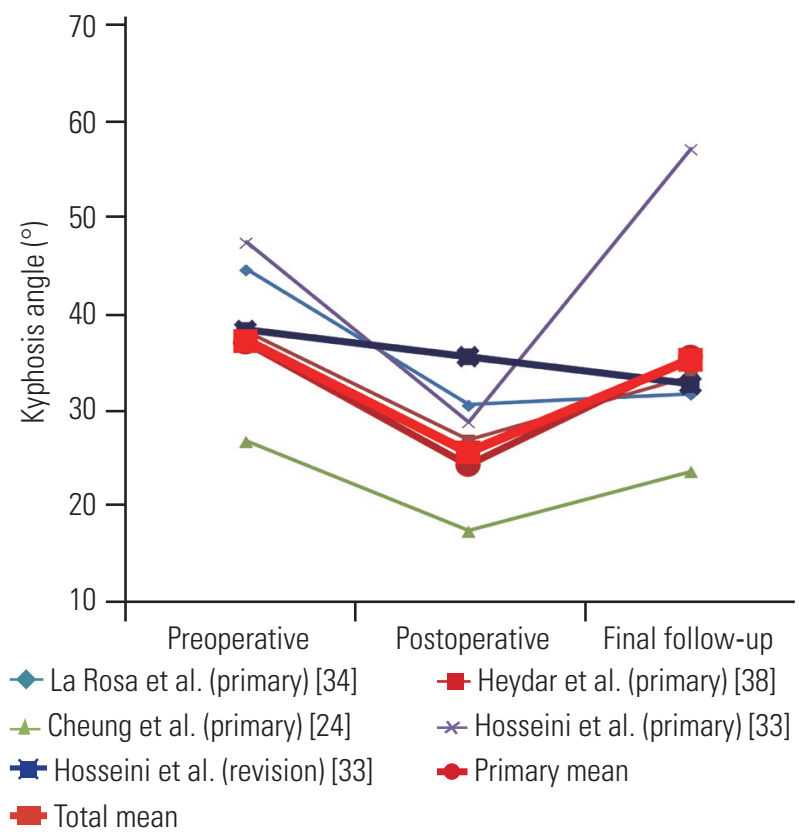

Fig. 3. The average kyphotic angle was $38.0^{\circ}$ preoperatively, changed to $26.1^{\circ}$ postoperatively, and was $36.0^{\circ}$ at the final follow-up. cases $[14,24,33,34,38,39]$. The average preoperative T1S1 length was $293.6 \mathrm{~mm}$, which increased to $320.3 \mathrm{~mm}$ postoperatively. At the final follow-up, T1-S1 length was

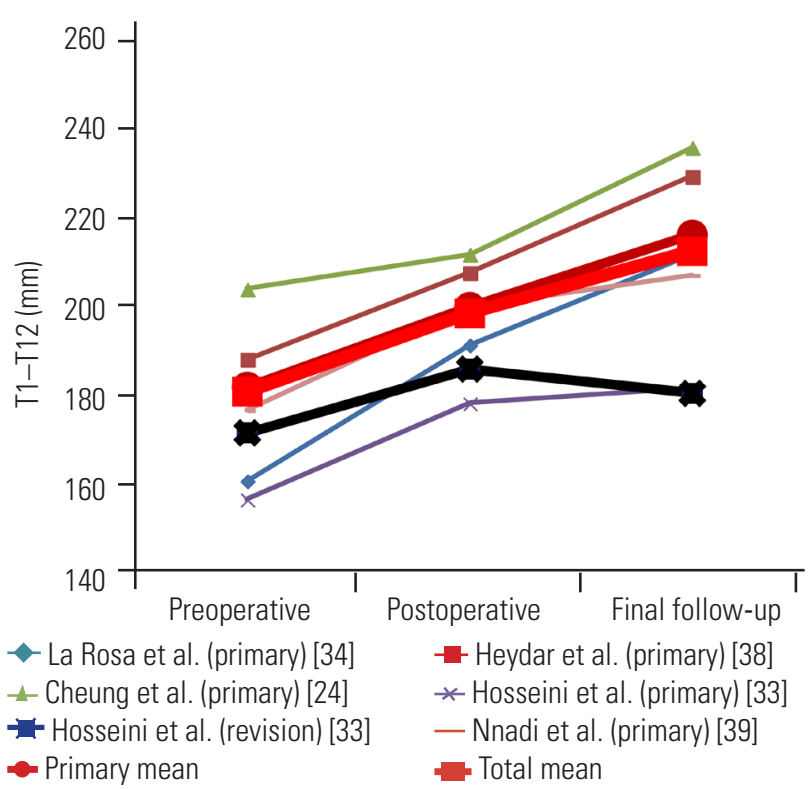

Fig. 4. The average preoperative T1-T12 length was $180.6 \mathrm{~mm}$ and increased to $198.3 \mathrm{~mm}$ postoperatively. At final follow-up, it was 212.3 $\mathrm{mm}$. No growth was observed after operation in the revision cases in the study of Hosseini et al. [33], on the contrary, it had slightly decreased.

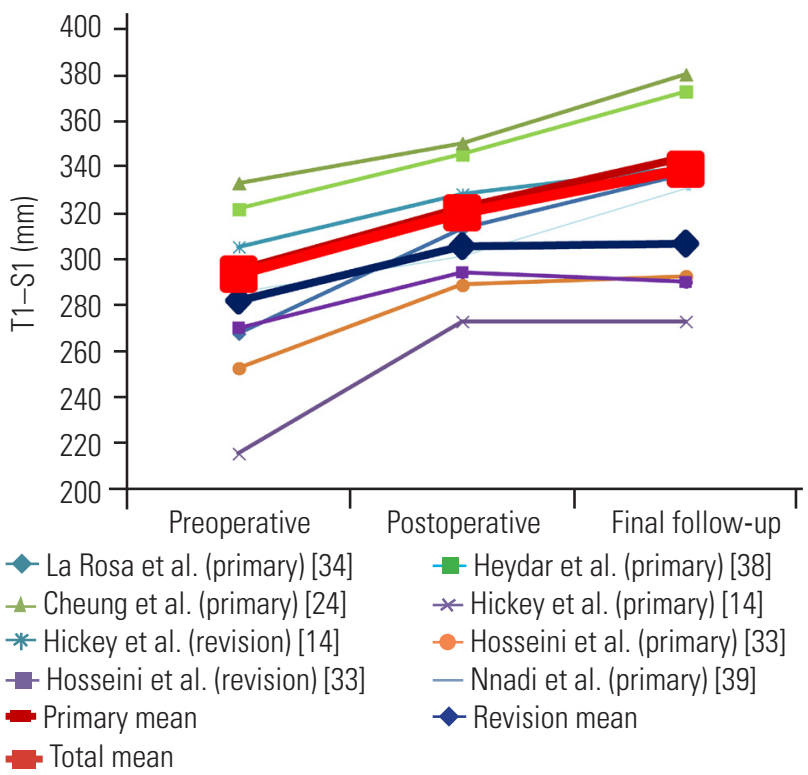

Fig. 5. The average preoperative T1-S1 length was $293.6 \mathrm{~mm}$ and increased to $320.3 \mathrm{~mm}$ postoperatively. At the final follow-up, it was $339.3 \mathrm{~mm}$. The average T1-S1 length of primary and revision subgroup was $295.5 \mathrm{~mm}$ and $282.0 \mathrm{~mm}$ preoperatively and increased to $322.6 \mathrm{~mm}$ and $305.8 \mathrm{~mm}$ postoperatively; at the final follow-up, these lengths were $344.5 \mathrm{~mm}$ and $306.9 \mathrm{~mm}$, respectively. 


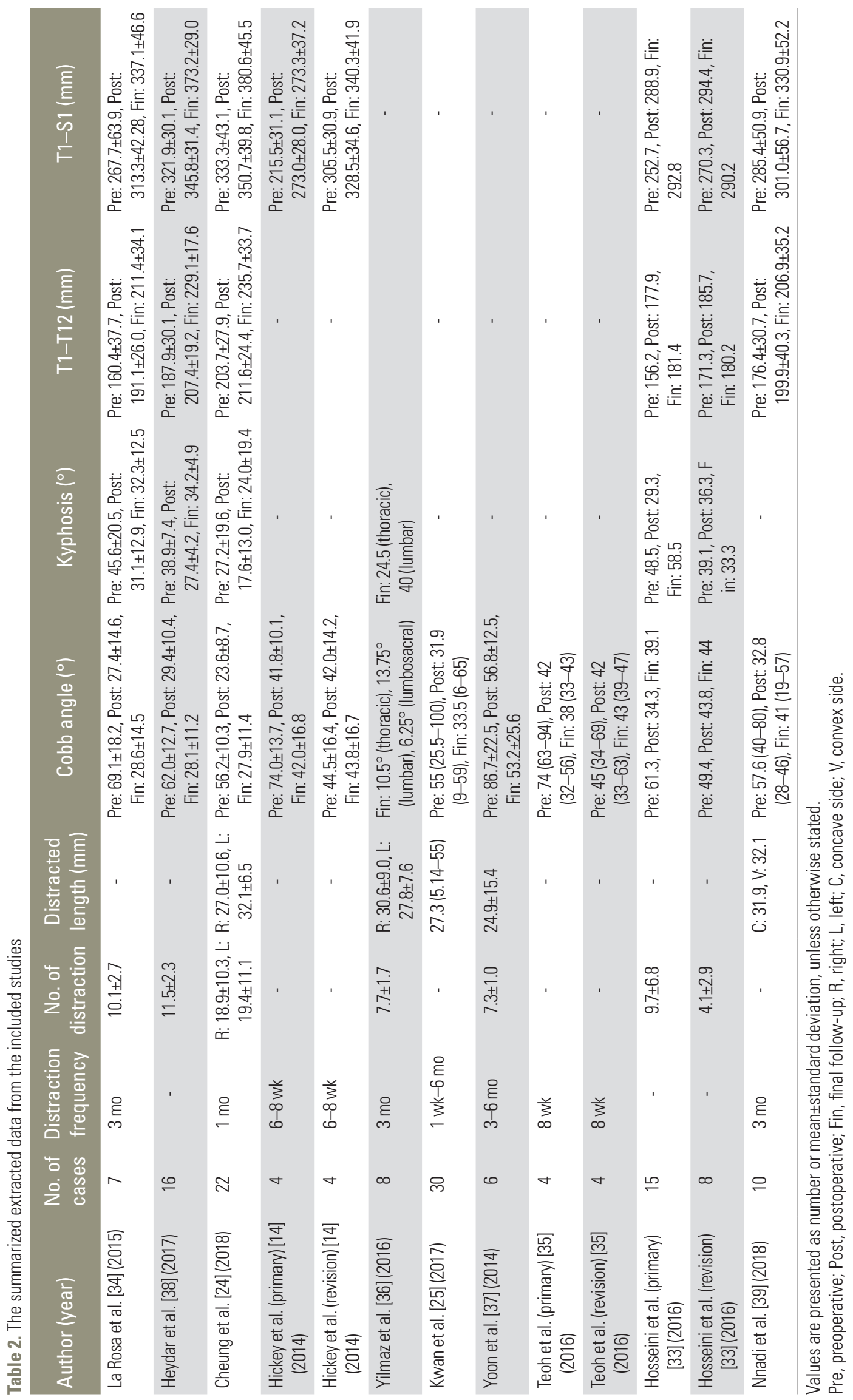


$339.3 \mathrm{~mm}$. The average T1-S1 lengths of the primary and revision subgroups were $295.5 \mathrm{~mm}$ and $282.0 \mathrm{~mm}$ preoperatively, increased to $322.6 \mathrm{~mm}$ and $305.8 \mathrm{~mm}$ postoperatively, and were $344.5 \mathrm{~mm}$ and $306.9 \mathrm{~mm}$ at the final follow-up, respectively (Fig. 5). All the extracted data are summarized in Table 2.

\section{Distraction frequency and distracted length}

Data of distraction frequency, number of distractions, and distracted length are summarized in Table 2. The distraction frequency was 1-2 months reported in studies by Cheung et al. [24], Hickey et al. [14], and Teoh et al. [35]. The distraction frequency was 3-6 months in studies conducted by La Rosa et al. [34], Yilmaz et al. [36], Nnadi et al. [39], and Yoon et al. [37]. The average postoperative distracted length was $28.3 \mathrm{~mm}$ (range of follow-up, 23-61 months) in the present systematic review. The average Cobb angle, kyphosis angle, T1-T12 length, and T1-S1 length in the cases with the higher distraction frequency
(1-2 months) were $2.6^{\circ}, 6.4^{\circ}, 24.1 \mathrm{~mm}$, and $25.3 \mathrm{~mm}$, respectively, which was slightly better than patients with lower distraction frequency (3-6 months) of $3.0^{\circ}, 1.2^{\circ}$, $12.5 \mathrm{~mm}$, and $27.3 \mathrm{~mm}$, respectively.

\section{Complications and unplanned reoperations}

Eight studies [14,25,33-35,38,39] reported complications, and seven studies [14,25,33-35,39] reported unplanned reoperations. Reasons for complications included rod breakage, failure of proximal foundation, failure of rod distraction, hook prominence, hook or screw pullout, proximal failure, proximal kyphosis, and infection. The complications and unplanned reoperations from the reported studies are summarized in Table 3.

The overall complication rate was $31 \%$ (95\% confidence interval [CI], 0.23-0.39), although there was significant heterogeneity $\left(I^{2}=71.4 \%, p<0.001\right)$. Therefore, we performed a sensitivity analysis and found that the category 'Heydar et al. (primary) [38]' was the source of the sig-

Table 3. The summarized complications and unplanned re-operation of included studies

\begin{tabular}{|c|c|c|}
\hline Author (year) & $\begin{array}{l}\text { No. of } \\
\text { cases }\end{array}$ & No. of complications and unplanned re-operation \\
\hline La Rosa et al. [34] (2015) & 7 & $\begin{array}{l}2 \text { Patients experienced rod breakage ( } 12 \text { and } 22 \text { months after surgery) ( } 1 \text { case the rod was attached with } \\
\text { a domino and } 1 \text { case the rod was substituted); } 1 \text { patient had a pull-out of } 2 \text { hooks at the top of the } \\
\text { construct } 9 \text { months after surgery (then substituted by } 2 \text { pedicle screws) }\end{array}$ \\
\hline Heydar et al. [38] (2017) & 16 & 1 Dislodged housing pin of the distraction unit and discontinued distraction at impaired side \\
\hline Hickey et al. [14] (2014) & 8 & $\begin{array}{l}1 \text { Fracture of single rod ( } 6 \text { months post surgery); } 1 \text { proximal screws pullout ( } 3 \text { months post surgery) and } \\
\text { proximal junctional kyphosis; } 2 \text { failure of construct to distract }\end{array}$ \\
\hline Kwan et al. [25] (2017) & 30 & $\begin{array}{l}14 \text { Unplanned re-operation: failure of rod distraction }(\mathrm{N}=6) \text {; failure of proximal foundation }(\mathrm{N}=3) \text {; proximal } \\
\text { failure with rod breakage }(\mathrm{N}=1) \text {; proximal failure with infection }(\mathrm{N}=1) \text {; rod breakage }(\mathrm{N}=1) \text {; infection }(\mathrm{N}=1) \text {; } \\
\text { coronal imbalance }(\mathrm{N}=1)\end{array}$ \\
\hline Yoon et al. [37] (2014) & 6 & 2 Unplanned re-operation: 1 prominent rod; 1 rod breakage \\
\hline Teoh et al. [35] (2016) & 8 & $\begin{array}{l}6 \text { Patients required } 8 \text { unplanned re-operation: non-functioning magnetic rod }(\mathrm{N}=1) \text {; proximal screw pull-out } \\
(\mathrm{N}=3) \text {; broken pin in magnetic rod and deep infection }(\mathrm{N}=1) \text {; broken magnetic; rod at distal end }(\mathrm{N}=2) \text {; } \\
\text { development of proximal junction kyphosis }(\mathrm{N}=1)\end{array}$ \\
\hline Hosseini et al. [33] (2016) & 23 & $\begin{array}{l}14 \text { Implant related complications occurred in } 10 \text { patients and final } 10 \text { unplanned re-operation: } 1 \text { patient } \\
\text { with } 2 \text { complications of pain caused by prominent rod on right side and right side pedicle screws out of } \\
\text { pedicle ( } 2 \text { unplanned re-operation); } 1 \text { upper hook prominent (1 unplanned re-operation); } 1 \text { patient with } \\
2 \text { complications of rod collapse and metalline substance around the rods ( } 1 \text { unplanned re-operation); } 1 \\
\text { bilateral rods didn't lengthen (1 unplanned re-operation); } 3 \text { rod collapse; } 1 \text { lower part of rod broken (1 } \\
\text { unplanned re-operation); } 1 \text { protrusion of wire through skin (1 unplanned re-operation); } 2 \text { broken rod (2 } \\
\text { unplanned re-operation); } 1 \text { rod foundation breakage (1 unplanned re-operation) }\end{array}$ \\
\hline Nnadi et al. [39] (2018) & 10 & $\begin{array}{l}5 \text { Patients with } 5 \text { serious adverse event and } 5 \text { adverse events, and } 6 \text { patients with unplanned re-operation: } \\
1 \text { pull-out of the proximal anchors ( } 1 \text { unplanned re-operation); } 1 \text { severe adverse event with recurrent } \\
\text { back pain ( } 1 \text { unplanned re-operation); } 1 \text { moderately severe adverse event with back pain, resolved spon- } \\
\text { taneously; } 1 \text { mild adverse event with back pain, resolved spontaneously; } 1 \text { had } 3 \text { serious adverse events, } \\
\text { resolved uneventfully and not related to device; } 4 \text { unplanned re-operation unrelated to device }\end{array}$ \\
\hline
\end{tabular}


A The Heydar et al. (primary) [38] is not omitted and results with significant heterogeneity.

Study

Primary subgroup

La Rosa et al. (primary) [34]

Heydar et al. (primary) [38]

Hickey et al. (primary) [14]

Kwan et al. (primary) [25]

Yoon et al. (primary) [37]

Hosseini et al. (primary) [33]

Nnadi et al. (primary) [39]

Subtotal $\left(P^{2}=69.1 \%, p=0.004\right)$

Revision subgroup

Hickey et al. (revision) [14]

Kwan et al. (revision) [25]

Hosseini et al. (revision) [33]

Subtotal $\left(P^{2}=0.0 \%, p=0.570\right)$

Mixed subgroup

Teoh et al. (mixed) [35]

Heterogeneity between

groups: $p=0.001$

Overall $\left(P^{2}=71.4 \%, p=0.000\right)$

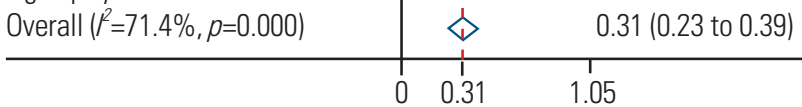

(B) The Heydar et al. (primary) [38] is omitted after sensitivity analysis and the results without heterogeneity now.

Study

Percentage (95\% Cl)

Primary subgroup

La Rosa et al. (primary) [34]

Hickey et al. (primary) [14]

Kwan et al. (primary) [25]

Yoon et al. (primary) [37]

Hosseini et al. (primary) [33]

Nnadi et al. (primary) [39]

Subtotal $\left(P^{2}=0.090 \%, p=0.0876\right)$

Revision subgroup

Hickey et al. (revision) [14]

Kwan et al. (revision) [25]

Hosseini et al. (revision) [33]

Subtotal $\left(P^{2}=0.0 \%, p=0.570\right)$

Mixed subgroup

Teoh et al. (mixed) [35]

Heterogeneity between

groups: $p=0.001$

Overall $\left(l^{2}=0.090 \%, p=0.685\right)$

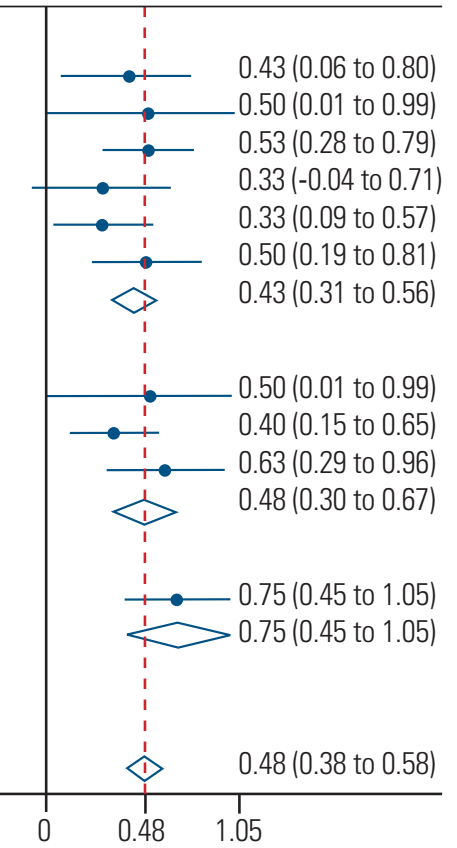

Fig. 6. (A, B) The forest plot showed the overall rate of patients with complications of $31 \%(95 \% \mathrm{Cl}, 0.23-0.39)$ but with significant heterogeneity $\left({ }^{2}=71.4 \%, p<0.001\right)$. After sensitivity analysis and the omission of the category 'Heydar et al. (primary) [38],' the overall rate of patients with complications was $48 \%(95 \% \mathrm{Cl}, 0.38-0.58)$, with no significant heterogeneity observed $\left(l^{2}=0.0 \%, p=0.685\right)$, primary and revision subgroup rate of $43 \%(95 \% \mathrm{Cl}, 0.31-0.56)$ and $48 \%(95 \% \mathrm{Cl}$, $0.30-0.67)$, respectively. $\mathrm{Cl}$, confidence interval.
A The Teoh et al. (primary) [35] is not omitted and results with significant heterogeneity.

Study

Percentage (95\% CI)

Primary subgroup

La Rosa et al. (primary) [34]

Kwan et al. (primary) [25]

Yoon et al. (primary) [37]

Teoh et al. (primary) [35]

Hosseini et al. (primary) [33]

Nnadi et al. (primary) [39]

Subtotal $\left(l^{2}=88.9 \%, p=0.000\right)$

Revision subgroup

Kwan et al. (revision) [25]

Teoh et al. (revision) [35]

Hosseini et al. (revision) [33]

Subtotal $\left(P^{2}=0.0 \%, p=0.570\right)$

Heterogeneity between

groups: $p=0.002$

Overall $\left(l^{2}=85.6 \%, p=0.000\right)$

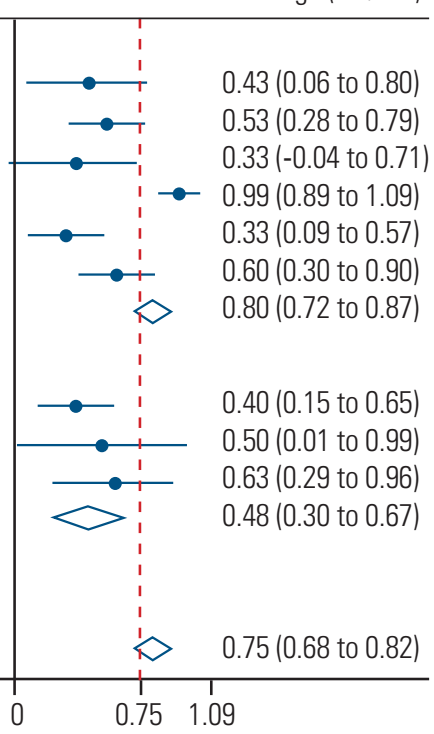

(B) The Teoh et al. (primary) [35] is omitted after sensitivity analysis and the results without heterogeneity now.

Study

Percentage (95\% Cl)

Primary subgroup

La Rosa et al. (primary) [34]

Kwan et al. (primary) [25]

Yoon et al. (primary) [37]

Hosseini et al. (primary) [33]

Nnadi et al. (primary) [39]

Subtotal $\left(P^{2}=0.0 \%, p=0.617\right)$

Revision subgroup

Kwan et al. (revision) [25]

Teoh et al. (revision) [35]

Hosseini et al. (revision) [33]

Subtotal $\left(P^{2}=0.0 \%, p=0.570\right)$

Heterogeneity between

groups: $p=0.768$

Overall $\left(l^{2}=0.0 \%, p=0.795\right)$

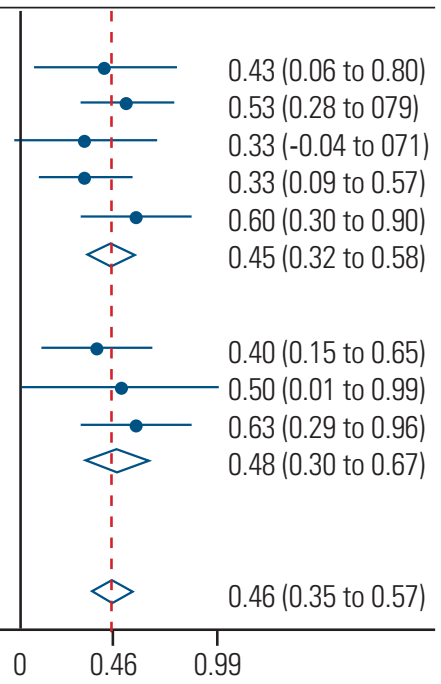

Fig. 7. (A, B) The forest plot shows pooled analysis found that the overall rate of patients with unplanned reoperation was 75\% (95\% $\mathrm{Cl}, 0.68-0.82)$, but with significant heterogeneity $\left(R^{2}=85.6 \%, p<0.001\right)$. After sensitivity analysis, the omission of the category 'Teoh et al. (primary) [35]' and then the overall rate of patients was 46\% (95\% $\mathrm{Cl}, 0.33-0.57)$. No significant heterogeneity was observed $\left(l^{2}=0.0 \%\right.$, $p=0.795)$. The primary and revision subgroup rate of patients with unplanned reoperation was $45 \%(95 \% \mathrm{Cl}, 0.32-0.58)$ and $48 \%(95 \% \mathrm{Cl}$, $0.30-0.67)$, respectively. $\mathrm{Cl}$, confidence interval.

nificant heterogeneity (Supplemental Fig. 1). The overall rate of patients with complications (after omission of the category 'Heydar et al. (primary) [38]') was 48\% (95\% 
CI, 0.38-0.58) with no significant heterogeneity observed $\left(I^{2}=0.0 \%, p=0.685\right)$. The rate of complications for the primary and revision subgroups was $43 \%$ (95\% CI, 0.31-0.56) and $48 \%$ (95\% CI, 0.30-0.67), respectively (Fig. 6).

A pooled analysis determined that the overall rate of patients with unplanned reoperation was 75\% (95\% CI, $0.68-0.82)$ with significant heterogeneity $\left(I^{2}=85.6 \%\right.$, $p<0.001)$. A sensitivity analysis found the category 'Teoh et al. (primary) [35]' was the source of the significant heterogeneity (Supplemental Fig. 2). The overall unplanned reoperation rate after omission of the category 'Teoh et al. (primary) [35]' was $46 \%$ (95\% CI, $0.33-0.57$ ), with no significant heterogeneity observed $\left(I^{2}=0.0 \%, p=0.795\right)$. The rate of unplanned reoperations in the primary and revision subgroups was $45 \%$ (95\% CI, $0.32-0.58$ ) and $48 \%$ (95\% CI, 0.30-0.67), respectively (Fig. 7).

\section{Discussion}

Since Cheung et al. [13] first reported on five cases of scoliosis treated with magnetically controlled growing rods in 2012 (of only two had a 2-year follow-up), magnetically controlled growing rods have become popularized worldwide $[40,41]$. However, most of the published literature present only preliminary results with a short-term followup period of less than 2 years, and thus results with at least a 2-year follow-up are still limited. Moreover, due to the relatively low incidence of severe early-onset scoliosis, the sample size in each published study is small, with the largest study by Kwan et al. [25] which included 30 cases. We systematically reviewed ten studies [14,24,25,33-39] with a total number of 116 cases.

The Cobb angle was significantly corrected after the initial operation in patients in the primary subgroup (from $65.9^{\circ}$ preoperative to $35.2^{\circ}$ postoperative). However, we found that for patients for whom the magnetically controlled growing rods were used as a revision, there was only a small change in the Cobb angle (from $47.2^{\circ}$ preoperative to $42.9^{\circ}$ postoperative). The original data showed an average change of $3^{\circ}$ in four revision cases in the study by Teoh et al. [35] and a 5.6 change in eight revision cases as reported by Hosseini et al. [33]. At the final follow-up, the improvements in Cobb angle were maintained. This result is mostly expected since in revision cases, most of the curves have already been corrected by the index operation, and thus, the exchange of the implant to magnetic growing rods facilitates noninvasive outpatient distrac- tions. We also found the Cobb angle was mostly corrected during the first operation, and although further frequent distractions increased the length, the average Cobb angle did not change significantly.

The average T1-T12 and T1-S1 lengths increased to17.7 $\mathrm{mm}$ and $26.7 \mathrm{~mm}$ after the initial operation, respectively. The magnetically controlled growing rods permit increases in T1-T12 and T1-S1 length after distractions, with an average of $16.3 \mathrm{~mm}$ and $19.0 \mathrm{~mm}$ at a follow-up of more than 2 years (range, 23-61 months), respectively. However, in a study by Hosseini et al. [33] in eight patients where magnetically controlled growing rods were used as a revision, the T1-T12 and T1-S1 lengths decreased from $185.7 \mathrm{~mm}$ and $294.4 \mathrm{~mm}$ postoperatively to 180.2 $\mathrm{mm}$ and $290.2 \mathrm{~mm}$, respectively, at the final follow-up. The average postoperation T1-S1 length in the revision subgroup was $305.8 \mathrm{~mm}$ and $306.9 \mathrm{~mm}$ at the final followup, a marginal $1.1 \mathrm{~mm}$ increase. A separate analysis found that the primary subgroup had a larger increase in T1T12 and T1-S1 lengths with an average of $16.3 \mathrm{~mm}$ and $21.9 \mathrm{~mm}$, respectively. In the study by Cheung et al. [13], the patients had an average of $29 \mathrm{~mm}$ increase in T1-S1 length 2 years after the operation, and similarly, La Rosa et al. [34] reported an average increase in the T1-S1 length of $24.2 \mathrm{~mm}$ after $31 \pm 5.1$ months (range, 26-41 months) of follow-up. Also, Hickey et al. [14] (primary subgroup) reported one patient who had proximal junctional kyphosis and a T1-S1 length of $256 \mathrm{~mm}$ which was decreased to $235 \mathrm{~mm}$ at the final follow-up; therefore, this data point likely diluted any average increase in length in their study.

Bess et al. [7] reviewed 140 patients with early-onset scoliosis who were treated with traditional growing rods and observed a total of 177 complications, with an average of 1.2 (range, $0-7$ ) complications per patient. Our subgroup analysis found the primary (42\%) and revision (48\%) subgroups had similar rates of complications. When all of the subgroups (primary, revision, and mixed) were combined, the overall rate of patients with complications was $48 \%$ (95\% CI, $0.38-0.58$ ), which is less than that of patients treated with traditional growing rods.

The overall unplanned reoperation rate after sensitivity analysis was approximately $46 \%$ (95\% CI, 0.35-0.57), which meant that almost half of patients had unplanned reoperations at more than 2 years (range, 23-61 months) of follow-up. However, traditional growing rods require at least 3-4 reoperations for distraction at 2 years. In the study conducted by Bess et al. [7], 140 patients underwent 
a total of 897 traditional growing rod surgical procedures; on an average, each patient underwent 6.4 procedures. Therefore, magnetically controlled growing rods offer a significant advantage of decreasing the rate of multiple reoperations, thus allowing for noninvasive distraction and reducing infection rate $[1,42,43]$.

Magnetically controlled growing rods have only been used in clinical practice for less than ten years since its first implantation in patients. There are several unresolved issues that require further investigation, such as the 'law of diminishing returns' after serial distraction [44], metal ion (titanium and possibly aluminum) release into serum [45], and long-term effects of tissue metallosis [27].

There are some limitations to the present systematic review that warrant discussion. First, all included studies were case series, and none were randomized controlled trials [46]. Therefore, the current evidence is still of relative low quality. Second, the sample size was still small, although our study represents the largest number of patients with a minimum of 2-year follow-up in the literature. Third, some identical cases may inadvertently been included in different studies, even though authors attempted to exclude known identical cases from the same clinical site. Fourth, data from some of the included studies only provided the mean but not the standard deviation; therefore, we could only calculate the mean values of Cobb angle, kyphosis, T1-T12, and T1-S1 length. Fifth, studies from different medical sites had different distraction frequencies and methodologies, which may thus contribute to the heterogeneity. To address this, we performed a sensitivity analysis to diminish this effect. Due to the apparent and now obvious advantages of magnetically controlled growing rods, it would be scientifically and medically unethical to conduct a randomized controlled study. Therefore, our present study provides the best evidence regarding clinical outcomes and reduced complications of magnetically controlled growing rods for the treatment of pediatric scoliosis at this time.

\section{Conclusions}

The present systematic review of studies who observed more than 2-year follow-up suggests that the use of magnetically controlled growing rods is an effective technique in the treatment of pediatric scoliosis as it permits spinal growth and is associated with fewer complications and unplanned reoperations compared to traditional growing rods. However, surgeons still must note the significant risk of complications and unplanned reoperations. Further studies should be conducted across multiple centers and include a full long-term follow-up of patients from implantation of magnetically controlled growing rods to final fusion.

\section{Conflict of Interest}

K.M.C.C. received grant and research support from Ellipse Technologies (now belonged to Nuvasive) and is consultants for the company. No potential conflict of interest relevant to this article was reported.

\section{Supplementary Materials}

Supplementary materials can be found via https://doi. org/10.31616/asj.2018.0272. Supplementary Table 1. PRISMA 2009 checklist. Supplementary Table 2. Joanna Briggs Institute critical appraisal checklist for case series of included studies. Supplementary Fig. 1. Sensitivity analysis indicating that the category of Heydar et al. (primary) [38] significantly contributed to the heterogeneity of complication rate. Supplementary Fig. 2. Sensitivity analysis indicating that the category of Teoh et al. (primary) [35] significantly contributed to the heterogeneity of rate of unplanned reoperations.

\section{References}

1. Kwan K. Editorial: advances in the treatment of early-onset scoliosis? J Orthop Surg (Hong Kong) 2015;23:277.

2. Poe-Kochert C, Shannon C, Pawelek JB, et al. Final fusion after growing-rod treatment for early onset scoliosis: is it really final? J Bone Joint Surg Am 2016;98:1913-7.

3. Pehrsson K, Larsson S, Oden A, Nachemson A. Long-term follow-up of patients with untreated scoliosis: a study of mortality, causes of death, and symptoms. Spine (Phila Pa 1976) 1992;17:1091-6.

4. Akbarnia BA. Management themes in early onset scoliosis. J Bone Joint Surg Am 2007;89 Suppl 1:42-54.

5. McMaster MJ, Macnicol MF. The management of progressive infantile idiopathic scoliosis. J Bone Joint Surg Br 1979;61:36-42.

6. Thompson GH, Akbarnia BA, Campbell RM Jr. 
Growing rod techniques in early-onset scoliosis. J Pediatr Orthop 2007;27:354-61.

7. Bess S, Akbarnia BA, Thompson GH, et al. Complications of growing-rod treatment for early-onset scoliosis: analysis of one hundred and forty patients. J Bone Joint Surg Am 2010;92:2533-43.

8. Akbarnia BA, Emans JB. Complications of growthsparing surgery in early onset scoliosis. Spine (Phila Pa 1976) 2010;35:2193-204.

9. Akbarnia BA, Mundis G, Salari P, Walker B, Pool S, Chang A. A technical report on the Ellipse Technologies device: a remotely expandable device for noninvasive lengthening of growing rod. J Child Orthop 2009;3:530-1.

10. Akbarnia BA, Mundis GM Jr, Salari P, Yaszay B, Pawelek JB. Innovation in growing rod technique: a study of safety and efficacy of a magnetically controlled growing rod in a porcine model. Spine (Phila Pa 1976) 2012;37:1109-14.

11. Akbarnia BA, Cheung K, Noordeen H, et al. Next generation of growth-sparing techniques: preliminary clinical results of a magnetically controlled growing rod in 14 patients with early-onset scoliosis. Spine (Phila Pa 1976) 2013;38:665-70.

12. Cheung J, Yiu K, Cheung K, et al. The best distraction frequency for optimizing spine and rod length gains with magnetically controlled growing rods. Spine Deform 2017;5:453-4.

13. Cheung KM, Cheung JP, Samartzis D, et al. Magnetically controlled growing rods for severe spinal curvature in young children: a prospective case series. Lancet 2012;379:1967-74.

14. Hickey BA, Towriss C, Baxter G, et al. Early experience of MAGEC magnetic growing rods in the treatment of early onset scoliosis. Eur Spine J 2014;23 Suppl 1:S61-5.

15. Cheung JP, Bow C, Samartzis D, Ganal-Antonio AK, Cheung KM. Clinical utility of ultrasound to prospectively monitor distraction of magnetically controlled growing rods. Spine J 2016;16:204-9.

16. Stokes OM, O’Donovan EJ, Samartzis D, Bow CH, Luk KD, Cheung KM. Reducing radiation exposure in early-onset scoliosis surgery patients: novel use of ultrasonography to measure lengthening in magnetically-controlled growing rods. Spine J 2014;14:2397404.

17. Cheung JP, Cahill P, Yaszay B, Akbarnia BA, Cheung
KM. Special article: update on the magnetically controlled growing rod: tips and pitfalls. J Orthop Surg (Hong Kong) 2015;23:383-90.

18. Cheung JP, Samartzis D, Cheung KM. A novel approach to gradual correction of severe spinal deformity in a pediatric patient using the magneticallycontrolled growing rod. Spine J 2014;14:e7-13.

19. Dahl B, Dragsted C, Ohrt-Nissen S, Andersen T, Gehrchen M. Use of a distraction-to-stall lengthening procedure in magnetically controlled growing rods: a single-center cohort study. J Orthop Surg (Hong Kong) 2018;26:2309499018779833.

20. Keskinen H, Helenius I, Nnadi C, et al. Preliminary comparison of primary and conversion surgery with magnetically controlled growing rods in children with early onset scoliosis. Eur Spine J 2016;25:3294300.

21. Lebon J, Batailler C, Wargny M, et al. Magnetically controlled growing rod in early onset scoliosis: a 30case multicenter study. Eur Spine J 2017;26:1567-76.

22. Skov ST, Wijdicks SP, Bunger C, Castelein RM, Li H, Kruyt MC. Treatment of early-onset scoliosis with a hybrid of a concave magnetic driver (magnetic controlled growth rod) and a contralateral passive sliding rod construct with apical control: preliminary report on 17 cases. Spine J 2018;18:122-9.

23. Cheung JP, Bow C, Samartzis D, Kwan K, Cheung KM. Frequent small distractions with a magnetically controlled growing rod for early-onset scoliosis and avoidance of the law of diminishing returns. J Orthop Surg (Hong Kong) 2016;24:332-7.

24. Cheung JP, Yiu KK, Samartzis D, Kwan K, Tan BB, Cheung KM. Rod lengthening with the magnetically controlled growing rod: factors influencing rod slippage and reduced gains during distractions. Spine (Phila Pa 1976) 2018;43:E399-405.

25. Kwan KYH, Alanay A, Yazici M, et al. Unplanned reoperations in magnetically controlled growing rod surgery for early onset scoliosis with a minimum of two-year follow-up. Spine (Phila Pa 1976) 2017;42:E1410-4.

26. Rushton PR, Siddique I, Crawford R, Birch N, Gibson MJ, Hutton MJ. Magnetically controlled growing rods in the treatment of early-onset scoliosis: a note of caution. Bone Joint J 2017;99-B:708-13.

27. Teoh KH, von Ruhland C, Evans SL, et al. Metallosis following implantation of magnetically controlled 
growing rods in the treatment of scoliosis: a case series. Bone Joint J 2016;98-B:1662-7.

28. Thakar C, Kieser DC, Mardare M, Haleem S, Fairbank J, Nnadi C. Systematic review of the complications associated with magnetically controlled growing rods for the treatment of early onset scoliosis. Eur Spine J 2018;27:2062-71.

29. Liberati A, Altman DG, Tetzlaff J, et al. The PRISMA statement for reporting systematic reviews and metaanalyses of studies that evaluate health care interventions: explanation and elaboration. J Clin Epidemiol 2009;62:e1-34.

30. Moher D, Liberati A, Tetzlaff J, Altman DG; PRISMA Group. Preferred reporting items for systematic reviews and meta-analyses: the PRISMA statement. PLoS Med 2009;6:e1000097.

31. Joanna Briggs Institute. JBI critical appraisal checklist for case series: Joanna Briggs Institute reviewer's manual: 2016 edition. Adelaide: Joanna Briggs Institute; 2016.

32. Akbarnia BA, Pawelek JB, Cheung KM, et al. Traditional growing rods versus magnetically controlled growing rods for the surgical treatment of early-onset scoliosis: a case-matched 2-year study. Spine Deform 2014;2:493-7.

33. Hosseini P, Pawelek J, Mundis GM, et al. Magnetically controlled growing rods for early-onset scoliosis: a multicenter study of 23 cases with minimum 2 years follow-up. Spine (Phila Pa 1976) 2016;41:1456-62.

34. La Rosa G, Oggiano L, Ruzzini L. Magnetically controlled growing rods for the management of earlyonset scoliosis: a preliminary report. J Pediatr Orthop 2017;37:79-85.

35. Teoh KH, Winson DM, James SH, et al. Magnetic controlled growing rods for early-onset scoliosis: a 4-year follow-up. Spine J 2016;16:S34-9.

36. Yilmaz B, Eksi MS, Isik S, Ozcan-Eksi EE, Toktas ZO, Konya D. Magnetically controlled growing rod in early-onset scoliosis: a minimum of 2-year follow-up. Pediatr Neurosurg 2016;51:292-6.

37. Yoon WW, Sedra F, Shah S, Wallis C, Muntoni F, Noordeen $\mathrm{H}$. Improvement of pulmonary function in children with early-onset scoliosis using magnetic growth rods. Spine (Phila Pa 1976) 2014;39:1196202.

38. Heydar AM, Sirazi S, Okay E, Kiyak G, Bezer M. Short segment spinal instrumentation in early-onset scoliosis patients treated with magnetically controlled growing rods: surgical technique and mid - shortterm outcomes. Spine (Phila Pa 1976) 2017;42:188894.

39. Nnadi C, Thakar C, Wilson-MacDonald J, et al. An NIHR-approved two-year observational study on magnetically controlled growth rods in the treatment of early onset scoliosis. Bone Joint J 2018;100-B:50715.

40. Figueiredo N, Kananeh SF, Siqueira HH, Figueiredo RC, Al Sebai MW. The use of magnetically controlled growing rod device for pediatric scoliosis. Neurosciences (Riyadh) 2016;21:17-25.

41. Metkar U, Kurra S, Quinzi D, Albanese S, Lavelle WF. Magnetically controlled growing rods for scoliosis surgery. Expert Rev Med Devices 2017;14:117-26.

42. Choi E, Yaszay B, Mundis G, et al. Implant complications after magnetically controlled growing rods for early onset scoliosis: a multicenter retrospective review. J Pediatr Orthop 2017;37:e588-92.

43. Hosseini P, Akbarnia BA. Magnetically controlled growing rods: a less invasive treatment for early onset scoliosis. AME Med J 2017;2:29.

44. Ahmad A, Subramanian T, Panteliadis P, WilsonMacdonald J, Rothenfluh DA, Nnadi C. Quantifying the 'law of diminishing returns' in magnetically controlled growing rods. Bone Joint J 2017;99-B:165864.

45. Yilgor C, Efendiyev A, Akbiyik F, et al. Metal ion release during growth-friendly instrumentation for early-onset scoliosis: a preliminary study. Spine Deform 2018;6:48-53.

46. Feinberg N, Matsumoto H, Hung CW, et al. Expert consensus and equipoise: planning a randomized controlled trial of magnetically controlled growing rods. Spine Deform 2018;6:303-7. 